\title{
Evolving Approaches to Metastatic Breast Cancer Patients Pre-treated with Anthracycline and Taxane
}

\author{
Shigehira Saji
}

Published online: 9 May 2013

(c) The Author(s) 2013. This article is published with open access at Springerlink.com

\begin{abstract}
Metastatic breast cancer is currently incurable and the goals of therapy focus on prolonging survival and maintaining quality of life by controlling symptoms and minimizing toxicity. Treatments for metastatic breast cancer include chemotherapeutic agents from various classes, such as taxanes, vinca alkaloids, anthracyclines and antimetabolites. This review provides an overview of chemotherapeutic agents for the treatment of metastatic breast cancer patients previously treated with anthracyclines and taxanes, focusing on a clinical evaluation of eribulin, the most recently approved agent for the treatment of metastatic breast cancer. Eribulin is a synthetic derivative of halichondrin B, a tumour growth inhibitor found in marine sponges, which prevents microtubule growth and sequesters the tubulin molecules into unusual aggregates, initiating apoptosis. Studies of eribulin have shown that the drug is effective in the treatment of previously treated metastatic breast cancer, and has an acceptable toxicity profile. Importantly, in the phase III EMBRACE study, eribulin treatment resulted in a survival advantage, a difficult endpoint to achieve with a single chemotherapeutic agent. An additional phase III study showed that eribulin has similar efficacy to capecitabine in women treated with no more than three prior therapies. Furthermore, pre-specified exploratory analyses suggest that particular patient subgroups may have greater therapeutic benefit with eribulin and may warrant further study to explore the potential mechanisms.
\end{abstract}

\section{S. Saji $(\bowtie)$}

Department of Target Therapy Oncology, Kyoto University

Graduate School of Medicine, 54 Shogoin Kawahara-cho,

Sakyo-ku, Kyoto 606-8507, Japan

e-mail: ss-saji@wa2.so-net.ne.jp

\section{Introduction}

Breast cancer is the most common cancer in women. In 2008, 1.38 million new cases of breast cancer were diagnosed worldwide, and there were over 458,000 deaths [1]. Over the last 25 years, the incidence of breast-cancer related deaths has declined in the USA and parts of Europe, mostly owing to improved detection and treatment [2]. However, survival in patients with breast cancer depends heavily on the stage of the tumour, with US statistics demonstrating a $98 \%$ survival rate at 5 years in patients with non-invasive disease, such as ductal carcinoma in situ, which decreases to $24 \%$ in patients with metastatic disease [3]. Unfortunately, approximately one-third of women with early-stage breast cancer will eventually develop metastatic disease [4], and metastatic breast cancer is currently incurable.

The goals of therapy in patients who have metastatic disease focus on prolonging survival and maintaining quality of life by controlling symptoms and minimizing toxicity. Treatment choice in breast cancer is influenced by the hormone receptor and human epidermal growth factor receptor 2 (HER2) status of the tumour, and patients with metastatic disease may benefit from treatment tailored to their individual genotype status. Several targeted therapies are under development, but systemic chemotherapy remains an important approach for patients with metastatic breast cancer, particularly in patients with hormonerefractory, hormone receptor-negative or rapidly progressing metastatic disease $[4,5]$.

This review provides an overview of chemotherapeutic agents for the treatment of metastatic breast cancer patients previously treated with anthracyclines and taxanes, focusing on a clinical evaluation of eribulin, the most recently approved agent for the treatment of metastatic breast cancer. 


\section{Chemotherapeutic Agents for Metastatic Breast Cancer}

Breast cancer can be treated with chemotherapeutic agents from various classes, including antimicrotubule agents such as taxanes and eribulin, anthracyclines and antimetabolites [6-9]. Taxanes and anthracyclines are commonly used for first-line treatment of breast cancer, but development of drug resistance to these agents upon tumour recurrence is common. Despite the high level of resistance in recurrent breast cancer, studies have shown that third-line treatments can extend the time of disease control in a significant number of patients [10]. Agents used for treatment of women with metastatic breast cancer who have been previously treated with anthracyclines and taxanes include eribulin, ixabepilone and capecitabine (Table 1) [11-13].

Whereas antimicrotubule agents such as taxanes and eribulin all act by sending the cell into apoptosis via mitotic arrest after tubulin binding, the mechanism of action of eribulin is unique amongst the antimicrotubule agents [14, 15]. Whereas paclitaxel inhibits microtubule shortening [14], eribulin prevents microtubule growth [15]. Eribulin binds to the plus ends of the microtubule [16], inhibiting microtubule dynamics by suppressing microtubule polymerization [15]. This in turn sequesters tubulin into non-functional aggregates [15].

Anthracyclines such as doxorubicin and epirubicin induce DNA intercalation and apoptosis of tumour cells [17]. Antimetabolites, which include capecitabine and gemcitabine, inhibit processes required for DNA synthesis $[11,18]$ and the oral 5-fluorouracil (5-FU) analogue S-1 (a combination of the prodrug tegafur and two modulators of 5-FU) acts following its biotransformation to cytotoxic nucleotides [19]. Other choices for breast cancer treatment include platinum analogues such as carboplatin and cisplatin, which induce DNA adduct formation [20], and irinotecan, which inhibits DNA synthesis via an interaction with topoisomerase I [21].
Several factors to be considered when selecting agents for patients previously treated with anthracyclines and taxanes include pre-treatment history, previous response, residual toxicity and tumour aggressiveness. The standard regimen for metastatic breast cancer patients previously treated with anthracyclines and taxanes remains to be established.

\section{Clinical and Pharmacological Evaluation of Eribulin}

\subsection{Pharmacological Properties}

Eribulin is a synthetic derivative of halichondrin B, a cellcycle progression inhibitor found in marine sponges [15]. Eribulin was approved for the treatment of metastatic breast cancer patients previously treated with anthracyclines and taxanes in the USA in 2010 [22] and in Europe and Japan in 2011 [23, 24].

Phase I studies show that eribulin exhibits linear pharmacokinetics. In patients with advanced solid tumours, the peak drug plasma concentration was $44-528 \mathrm{ng} / \mathrm{mL}$ after single doses of eribulin of $0.25-4.0 \mathrm{mg} / \mathrm{m}^{2}$ [25]. Eribulin does not accumulate after multiple doses and is rapidly and extensively distributed [25]. In a phase I study of eribulin in patients with advanced solid tumours, the mean half-life was $46.5 \mathrm{~h}$ [25]. A similarly prolonged half-life was seen in a dose-ranging study of eribulin in Japanese patients with refractory solid tumours $(36.4-59.9 \mathrm{~h}$ with doses of $0.7-2.0 \mathrm{mg} / \mathrm{m}^{2}$ (Table 2) [26]. Eribulin exhibited triphasic pharmacokinetics with a long terminal half-life, high volume of distribution and low urinary clearance. This study was conducted to investigate higher doses of eribulin and to determine the dose-limiting toxicities (DLT), the recommended dose and the maximum tolerated dose in Japanese patients. As expected, the pharmacokinetic parameters of $C_{\max }$ and area under the drug concentration-time curve (AUC) of eribulin increased with each dose level (Table 2), and an increase in dose correlated with the incidence of

Table 1 Chemotherapeutic agents for metastatic breast cancer: mechanism of action [11-13, 17-21]

\begin{tabular}{|c|c|c|}
\hline Drug class & Agents & Mechanism of action \\
\hline Anthracyclines & Doxorubicin, epirubicin & DNA intercalation and induction of cell death \\
\hline Antimetabolites & Capecitabine, S-1, gemcitabine & Inhibits processes required for DNA synthesis \\
\hline \multirow[t]{5}{*}{ Antimicrotubule agents } & Paclitaxel & Stabilizes microtubules by inhibiting the shortening of microtubules \\
\hline & Docetaxel & \\
\hline & Ixabepilone & \\
\hline & Eribulin & Inhibits microtubules by suppressing microtubule growth at the plus end \\
\hline & Vinorelbine & $\begin{array}{l}\text { Inhibits microtubules by inhibiting the polymerization of tubulin dimers } \\
\text { and depolymerization }\end{array}$ \\
\hline Platinum analogues & Carboplatin, cisplatin & Induces DNA adduct formation and cell death \\
\hline Topoisomerase inhibitor & Irinotecan & Interferes with DNA coiling to inhibit transcription and replication \\
\hline
\end{tabular}


Table 2 Pharmacokinetic parameters and dose-limiting toxicities in the phase I study of eribulin in Japanese patients with advanced solid tumours [26]

\begin{tabular}{lllll}
\hline & \multicolumn{2}{l}{ Eribulin dose } & & \\
\cline { 2 - 5 } & $0.7 \mathrm{mg} / \mathrm{m}^{2}(n=3)$ & $1.0 \mathrm{mg} / \mathrm{m}^{2}(n=3)$ & $1.4 \mathrm{mg} / \mathrm{m}^{2}(n=6)$ & $2.0 \mathrm{mg} / \mathrm{m}^{2}(n=3)$ \\
\hline$C_{\max }, \mathrm{ng} / \mathrm{mL}$ & $288.5 \pm 43.0$ & $380.6 \pm 52.9$ & $519.4 \pm 107.2$ & $717.6 \pm 104.3$ \\
$\mathrm{AUC}_{0-\infty}, \mathrm{ng} \cdot \mathrm{h} / \mathrm{mL}$ & $299.2 \pm 124.5$ & $379.6 \pm 65.2$ & $672.7 \pm 113.7$ & $1,370.1 \pm 282.2$ \\
$t_{1 / 2}, \mathrm{~h}$ & $36.4 \pm 11.2$ & $42.9 \pm 10.9$ & $39.4 \pm 8.3$ & $59.9 \pm 13.4$ \\
$\mathrm{DLT}^{\mathrm{a}}, n(\%)$ & 0 & 0 & $2(33)^{\mathrm{b}}$ & $3(50)^{\mathrm{c}}$ \\
\hline
\end{tabular}

All data provided as mean \pm standard deviation unless otherwise stated

$A U C_{0-\infty}$ area under the drug concentration-time curve from time 0 to infinity, $D L T$ dose-limiting toxicities, $C_{\max }$ peak drug concentration, $h$ hours, $n$ number, $t_{1 / 2}$ terminal half-life

${ }^{a}$ Assessed in cycle 1 of eribulin treatment

${ }^{\mathrm{b}}$ Grade 4 neutropenia and grade 3 febrile neutropenia resulting in omission of the day 8 dose

${ }^{c}$ Grade 4 neutropenia, grade 3 neutropenia and grade 3 febrile neutropenia resulting in omission of the day 8 dose

adverse events [26]. This phase I study established the recommended dose of $1.4 \mathrm{mg} / \mathrm{m}^{2}$. Maximum tolerated dose (MTD) was $2.0 \mathrm{mg} / \mathrm{m}^{2}$ and the main DLT was neutropenia, which was smoothly recovered and manageable. These observations suggest that eribulin-related adverse events can be managed by the appropriate dose modifications. On the basis of this study and others to be discussed below, dose delay or dose reduction to 1.1 and $0.7 \mathrm{mg} / \mathrm{m}^{2}$ is recommended upon the incidence of severe adverse events.

\subsection{Clinical Properties}

\subsubsection{Phase II Studies}

In phase II studies, eribulin exhibited efficacy in patients with metastatic breast cancer who had previously been heavily treated with other chemotherapeutic agents. Two open-label, single-arm studies investigated the efficacy and tolerability of eribulin in 103 and 291 patients with metastatic breast cancer previously treated with an anthracycline and a taxane (study 201; NCT00097721) [27] or an anthracycline, taxane and capecitabine (study 211; NCT00246090) [28], respectively. In the per-protocol population of the smaller study $(n=87)$, eribulin had an overall response rate of $11.5 \%$, whereas patients in the larger study had an overall response rate of $9.3 \%$; in both studies, all responses were considered partial [27, 28]. In the smaller study, the clinical benefit rate, which includes patients demonstrating a response and those with stable disease for more than 6 months, was $17.2 \%$ [27]. Patients had a median progression-free survival of 2.6 months in both studies, and median overall survival was 9.0 months [27] and 10.4 months [28] (Table 3).

In Japanese patients with metastatic breast cancer previously treated with an anthracycline and a taxane (study 221) [29], eribulin appears to have a better efficacy than that observed in the others mentioned in Table 3. This open-label study of 80 patients who received $1.4 \mathrm{mg} / \mathrm{m}^{2}$ of eribulin demonstrated that eribulin had an objective clinical response rate of $21.3 \%$ and a clinical benefit rate of $27.5 \%$ in this patient population. However, this improved efficacy may be in part due to patient characteristics. In the previous two studies, patients had received a median of four previous regimens of chemotherapy containing an anthracycline plus a taxane and an anthracycline, taxane and capecitabine combination, respectively. In study 221, patients had received a median of three previous regimens of chemotherapy containing an anthracycline and a taxane. When the objective response rate was assessed according to the number of previous chemotherapy regimens in the metastatic setting, a higher response rate of $36 \%$ was observed in patients who had no or one previous regimen, and patients who had a median of two or more previous regimens had a decrease in response. In addition, further investigation is needed to evaluate whether pharmacogenetic variation contributes to eribulin efficacy and safety, because P-glycoprotein (P-gp) may be involved in eribulin disposition and polymorphism of $M D R 1$, the gene encoding P-gp, affects chemotherapeutic outcome.

\subsubsection{Phase III Studies}

Two phase III studies have investigated the efficacy of eribulin in metastatic breast cancer. EMBRACE (study 305; NCT00388726) compared eribulin with the physician's choice of therapy in 762 patients, and another study compared eribulin with capecitabine in 1,102 women previously treated with no more than three regimens (study 301; NCT00337103) [30, 31].

The encouraging results of the three phase II trials discussed previously led to the initiation of the phase III EMBRACE study—a randomized, open-label, multinational 
Table 3 Phase II studies of eribulin in patients with metastatic breast cancer who have previously received an anthracycline and taxane

\begin{tabular}{|c|c|c|c|}
\hline & $201[27]$ & $211[28]$ & $221[29]$ \\
\hline$n$ & 103 & 291 & 80 \\
\hline Prior chemotherapy & $\begin{array}{l}\text { Any prior regimen of chemotherapy } \\
\text { with } \mathrm{A} \text { and } \mathrm{T} \text { (median } 4 \text { ) }\end{array}$ & $\begin{array}{l}2-5 \text { prior regimens of chemotherapy } \\
\text { with } \mathrm{A}, \mathrm{T} \text { and CAP (median } 4)\end{array}$ & $\begin{array}{l}\leq 3 \text { prior regimens of chemotherapy } \\
\text { including } \mathrm{A} \text { and } \mathrm{T} \text { (median } 3 \text { ) }\end{array}$ \\
\hline Dosing schedule & $\begin{array}{l}1.4 \mathrm{mg} / \mathrm{m}^{2} \mathrm{IV} \text { inf } \\
\mathrm{d} 1+8+15 \mathrm{q} 4 \mathrm{w} \\
1.4 \mathrm{mg} / \mathrm{m}^{2} \mathrm{IV} \text { inf } \mathrm{d} 1+8 \\
\mathrm{q} 3 \mathrm{w}\end{array}$ & $\begin{array}{l}1.4 \mathrm{mg} / \mathrm{m}^{2} \mathrm{IV} \inf \mathrm{d} 1+8 \\
\mathrm{q} 3 \mathrm{w}\end{array}$ & $\begin{array}{l}1.4 \mathrm{mg} / \mathrm{m}^{2} \mathrm{IV} \inf \mathrm{d} 1+8 \\
\mathrm{q} 3 \mathrm{w}\end{array}$ \\
\hline \multicolumn{4}{|l|}{ Tumour response } \\
\hline PR $(\%)$ & $\begin{array}{l}11.5 \text { [total] } \\
10.2 \text { [q4w cohort] } \\
14.3 \text { [q3w cohort] }\end{array}$ & 9.3 & 21.3 \\
\hline $\mathrm{SD}, \%$ & $\begin{array}{l}11.5 \text { [total] } \\
10.2 \text { [q4w cohort] } \\
14.3 \text { [q3w cohort] }\end{array}$ & 46.5 & 42.5 \\
\hline $\mathrm{ORR}^{\mathrm{a}}(\%)$ & $\begin{array}{l}11.5 \text { [total] } \\
10.2 \text { [q4w cohort] } \\
14.3 \text { [q3w cohort] }\end{array}$ & 9.3 & 21.3 \\
\hline $\mathrm{CBR}^{\mathrm{b}}(\%)$ & $\begin{array}{l}17.2 \text { [total] } \\
11.9 \text { [q4w cohort] } \\
28.6[\mathrm{q} 3 \mathrm{w} \text { cohort] }\end{array}$ & 17.1 & 27.5 \\
\hline $\begin{array}{l}\text { Median duration of } \\
\text { response (months) }\end{array}$ & 5.6 & 4.1 & 3.9 \\
\hline Median PFS (months) & 2.6 & 2.6 & 3.7 \\
\hline Median OS (months) & 9.0 & 10.4 & 11.1 \\
\hline
\end{tabular}

$A$ anthracycline, $C A P$ capecitabine, $C B R$ clinical benefit rate, $d$ day, $I V$ inf intravenous infusion, $O R R$ objective response rate, $O S$ overall survival, $P F S$ progression-free survival, $P R$ partial response, $q X w$ every $X$ weeks, $S D$ stable disease, $T$ taxane

${ }^{a}$ Objective response rate $=$ complete response + partial response

${ }^{\mathrm{b}}$ Clinical benefit rate $=$ complete response + partial response + stable disease $\geq 6$ months

study that investigated the efficacy of eribulin in heavily pretreated women with locally recurrent or metastatic breast cancer [30]. Patients were required to have previously received between two and five chemotherapy regimens including an anthracycline and a taxane, and two or more regimens for locally recurrent or metastatic breast cancer. A dosage of $1.4 \mathrm{mg} / \mathrm{m}^{2}$ of eribulin was administered intravenously over 2-5 min on days 1 and 8 of a 21-day treatment cycle, and patients in the treatment of physician's choice (TPC) group received single-agent chemotherapy, cancer treatment-approved biological treatment, hormonal therapy, radiotherapy or symptomatic treatment [30]. The proposed TPC was chosen for each patient and confirmed before central randomization. In the TPC arm, $96 \%$ received chemotherapy including vinorelbine, gemcitabine and capecitabine, $4 \%$ received hormonal therapy but no patient received supportive care alone. The primary endpoint of the EMBRACE study was overall survival.
Eribulin significantly increased the median overall survival of patients compared with the TPC group (13.1 vs 10.6 months; hazard ratio [HR] $0.81,95 \%$ confidence interval $[\mathrm{CI}] 0.66,0.99 ; p=0.041$; Table 4$)$. In the eribulin treatment group there were 274 deaths $(54 \%)$ compared with $148(58 \%)$ in the TPC group; corresponding 1-year survival rates were 53.9 and $43.7 \%$, respectively [30]. The median progression-free survival (assessed by investigator review) was also significantly prolonged with eribulin treatment (HR 0.76; $95 \%$ CI 0.64, 0.90; $p=0.002$; Table 4); however, when assessed by independent review the difference in progression-free survival no longer appeared significant (HR 0.87; $95 \%$ CI 0.71 , 1.05; $p=0.137$; Table 4).

In patients with measurable disease, significantly more patients had an objective response (assessed by independent review) in the eribulin treatment group (12\%) compared with the TPC group ( $5 \% ; p=0.002)$ (Table 4). The 
Table 4 Phase III studies of eribulin in patients with metastatic breast cancer who have previously received an anthracycline and taxane

\begin{tabular}{|c|c|c|c|c|c|c|}
\hline & \multicolumn{4}{|c|}{305 (EMBRACE) [30] } & \multicolumn{2}{|l|}{$301[31]$} \\
\hline & Eribulin & & TPC & & Eribulin & CAP \\
\hline$n$ & 508 & & 254 & & 554 & 548 \\
\hline \multirow[t]{2}{*}{ Median OS, months } & $13.1^{*}$ & & 10.6 & & $15.9^{\dagger}$ & 14.5 \\
\hline & $\begin{array}{l}\text { Independent } \\
\text { review }\end{array}$ & $\begin{array}{l}\text { Investigator } \\
\text { review }\end{array}$ & $\begin{array}{l}\text { Independent } \\
\text { review }\end{array}$ & $\begin{array}{l}\text { Investigator } \\
\text { review }\end{array}$ & $\begin{array}{l}\text { Independent } \\
\text { review }\end{array}$ & $\begin{array}{l}\text { Independent } \\
\text { review }\end{array}$ \\
\hline Median PFS, months & 3.7 & $3.6^{*}$ & 2.2 & 2.2 & 4.1 & 4.2 \\
\hline \multicolumn{7}{|l|}{ Tumour response $(\%)$} \\
\hline $\mathrm{CR}$ & 1 & $<1$ & 0 & 0 & NR & NR \\
\hline PR & 12 & 13 & 5 & 7 & NR & NR \\
\hline SD & 44 & 47 & 45 & 45 & NR & NR \\
\hline $\mathrm{ORR}^{\mathrm{a}}$ & $12^{\S}$ & $13^{\top}$ & 5 & 7 & 11 & 12 \\
\hline $\mathrm{CBR}^{\mathrm{b}}$ & 23 & 28 & 17 & 20 & NR & NR \\
\hline
\end{tabular}

$C A P$ capecitabine, $C B R$ clinical benefit rate, $C R$ complete response, $N R$ not reported in meeting abstract, $O R R$ objective response rate, $O S$ overall survival, $P F S$ progression-free survival, $P R$ partial response, $S D$ stable disease, $T P C$ treatment of physician's choice

$* p=0.041 \mathrm{vs} \mathrm{TPC} ;{ }^{\dagger} p=0.056$ vs CAP; ${ }^{*} p=0.002 \mathrm{vs} \mathrm{TPC} ;{ }^{\S} p=0.002 \mathrm{vs} \mathrm{TPC} ;{ }^{\bullet} p=0.028 \mathrm{vs}$ TPC

${ }^{\text {a }}$ Objective response rate $=$ complete response + partial response

${ }^{\mathrm{b}}$ Clinical benefit rate $=$ complete response + partial response + stable disease $\geq 6$ months

clinical benefit rates were $23 \%(95 \%$ CI 18.9, 26.7) for eribulin and $17 \%(12.1,22.5)$ in the TPC group.

On the basis of the demonstration of a statistically significant prolongation of overall survival, eribulin mesylate was approved by the US Food and Drug Administration (FDA). This approval highlights the appropriate use of an innovative trial design and shows that improvement in overall survival is an achievable endpoint in the setting of advanced breast cancer.

Study 301 was a phase III, randomized, open-label, multinational study that also investigated the efficacy of eribulin in heavily pre-treated women with locally recurrent or metastatic breast cancer [31]. Patients were required to have previously received at most three chemotherapy regimens (at most two for advanced disease) with each regimen including an anthracycline or a taxane. Patients were randomized to either $1.4 \mathrm{mg} / \mathrm{m}^{2}$ of eribulin (administered intravenously over $2-5 \mathrm{~min}$ on days 1 and 8 of a 21-day treatment cycle) or oral capecitabine $\left(1,250 \mathrm{mg} / \mathrm{m}^{2}\right.$ twice daily on days 1-14 of a 21-day treatment cycle) [31]. The co-primary endpoints of study 301 were overall survival and progression-free survival.

Like the EMBRACE study, eribulin increased the median overall survival of patients compared with capecitabine ( 15.9 vs 14.5 months; HR $0.88,95 \%$ CI 0.77 , $1.00 ; p=0.056$; Table 4), although this difference was not statistically significant. In contrast, the median progression-free survival of both arms was almost identical (assessed by independent review) (Table 4). Similarly, in patients with measurable disease, there was no apparent difference in the proportion of patients who had an objective response rate (assessed by independent review) in the eribulin treatment group (11\%) compared with capecitabine (12\%) (Table 4).

Pre-specified exploratory analyses of the phase III trials discussed here suggest that particular patient subgroups may have greater therapeutic benefit with eribulin (Table 5). In particular, patients who are HER2 negative, oestrogen receptor negative or triple negative had significantly longer overall survival rates with eribulin treatment compared with capecitabine in study 301, as presented at the 2012 San Antonio Breast Cancer Symposium (Table 5) [31, 32]. However, although overall survival was prolonged in certain subgroups of patients receiving eribulin in study 301, the objective response rate and progression-free survival were similar between eribulin and capecitabine treatment in all subgroups assessed. This may be due to several factors: (1) patients receiving eribulin were allowed to cross over to capecitabine, whereas patients receiving capecitabine were allowed to receive eribulin less frequently, owing to the limited market access prior to approval; (2) more patients receiving eribulin may maintain better quality of life and accept a subsequent chemotherapy regimen owing to its lower toxicity; or (3) eribulin might have a promoting effect on the clinical activity of the subsequent chemotherapy regimen through the alteration of tumour phenotype, although this possibility is currently just speculation. Further basic research and clinical investigations focusing on these ideas are warranted to determine the possible cause of the increase in overall survival with eribulin. 
Table 5 Subgroup analysis of overall survival in the phase III studies of eribulin by human epidermal growth factor receptor 2 (HER2) and oestrogen receptor (ER) status

\begin{tabular}{|c|c|c|c|c|c|c|}
\hline & \multicolumn{3}{|c|}{305 (EMBRACE) [30] } & \multicolumn{3}{|c|}{$301[31,32]$} \\
\hline & \multicolumn{2}{|c|}{ OS (months) } & \multirow[t]{2}{*}{$\mathrm{HR}(95 \% \mathrm{CI})$} & \multicolumn{2}{|c|}{ OS (months) } & \multirow[t]{2}{*}{$\mathrm{HR}(95 \% \mathrm{CI})$} \\
\hline & Eribulin & TPC & & Eribulin & CAP & \\
\hline Total & 13.2 & 10.5 & $0.81(0.66,0.99)$ & 15.9 & 14.5 & $0.88(0.77,1.00)$ \\
\hline HER2+ & 11.3 & 9.1 & $0.76(0.47,1.24)$ & 14.3 & 17.1 & $0.97(0.69,1.36)$ \\
\hline HER2- & 13.2 & 10.5 & $0.81(0.64,1.02)$ & 15.9 & 13.5 & $0.84(0.72,0.98)$ \\
\hline $\mathrm{ER}+$ & 13.8 & 11.4 & $0.81(0.63,1.04)$ & 18.2 & 16.8 & $0.90(0.74,1.09)$ \\
\hline ER- & 10.2 & 7.8 & $0.78(0.54,1.13)$ & 14.4 & 10.5 & $0.78(0.64,0.96)$ \\
\hline $\mathrm{TN}$ & 9.5 & 7.0 & $0.71(0.46,1.10)$ & 14.4 & 9.4 & $0.70(0.55,0.91)$ \\
\hline
\end{tabular}

$C A P$ capecitabine, $E R$ oestrogen receptor, $H E R 2$ human epidermal growth factor receptor 2, $T N$ triple negative, $T P C$ treatment of physician's choice

\subsection{Tolerability}

Phase I studies have suggested that eribulin doses of $1.0-2.0 \mathrm{mg} / \mathrm{m}^{2}$ result in a manageable toxicity profile, and as a result the approved dosage of eribulin is a $2-5 \mathrm{~min}$ infusion of $1.4 \mathrm{mg} / \mathrm{m}^{2}$ on days 1 and 8 of a cycle lasting 21 days [12, 25, 26, 33]. Eribulin continued to exhibit an acceptable toxicity profile in both phase II [27-29] and phase III [30, 31] studies.

Consistent with the findings of the phase II trials [2729], in the EMBRACE trial adverse events were reported in 497 (99\%) patients receiving eribulin and 230 (93\%) patients receiving the TPC; of these, $126(25 \%)$ and 64 (26\%) patients reported serious adverse events [30]. The most common adverse events in either treatment group were asthenia or fatigue (54 and $40 \%$ of patients receiving eribulin and the TPC, respectively) and neutropenia (52 and $30 \%$, respectively). More patients receiving eribulin reported grade 3 or 4 neutropenia ( 45 vs $21 \%$ ), leukopenia (14 vs $6 \%$ ) or peripheral neuropathy ( 8 vs $2 \%$ ) [30].

Peripheral neuropathy was the most common adverse event leading to discontinuation of eribulin in the EMBRACE trial, with $24(5 \%)$ patients discontinuing treatment [30]. However, the incidence of peripheral neuropathy was similar in the eribulin treatment group (overall, $35 \%$ of patients; grade $3,8 \%$; grade $4,<1 \%$ ) and the taxane (overall, $45 \%$ of patients; grade $3,5 \%$; no grade 4 ) treatment group [30].

Similarly, the adverse events reported in study 301 were consistent with the previously known side effects of eribulin [31]. Adverse events were reported in $94.1 \%$ of patients receiving eribulin and $90.5 \%$ of patients receiving capecitabine; 17.5 and $21.1 \%$ of patients reported serious adverse events [31]. More patients receiving eribulin had neutropenia (54 vs $16 \%$ ) and leukopenia (31 vs $10 \%$ ); however, the incidence of anaemia, thrombocytopenia and febrile neutropenia was similar between treatment groups
[31]. Other common adverse events reported in patients receiving eribulin included alopecia (35\%), nausea (22\%), fatigue (17\%) and asthenia (15\%). Peripheral sensory neuropathy was observed in $13 \%$ of patients (grade 3, $4 \%$ of patients; no grade 4) [31].

\section{Ongoing Studies of Eribulin and Other Agents}

There are several ongoing studies investigating eribulin in breast cancer, including those investigating eribulin in the neo-adjuvant [34-38] and adjuvant setting [39-41], in patients with metastatic disease [42-49], and in combination with other anti-cancer agents $[34,37-40,42,43,45-$ 49] (Table 6).

So far, preliminary results of three studies of eribulin have been presented and suggest that eribulin would be efficacious and well tolerated as a treatment in other breast cancer populations. Preliminary results of two ongoing clinical trials that are investigating eribulin as first-line therapy either as monotherapy (NCT01268150) [50] or combination therapy (NCT01269346) [51] were presented at the 2012 San Antonio Breast Cancer Symposium. These results showed that as first-line therapy for patients with locally recurrent or metastatic breast cancer, eribulin appears to have anti-tumour activity and an acceptable safety profile, both when given as monotherapy and in combination with trastuzumab [50, 51].

The treatment of early-stage breast cancer with eribulin is also being investigated (NCT01328249) and preliminary results of this trial were presented at the 2012 San Antonio Breast Cancer Symposium [52]. This study, which is investigating the efficacy and safety of adjuvant eribulin in patients with early-stage breast cancer who have received dose-dense doxorubicin and cyclophosphamide, suggests that eribulin has an acceptable safety profile in this patient group. 
Table 6 Ongoing clinical studies investigating eribulin in patients with breast cancer

\begin{tabular}{|c|c|c|c|c|c|}
\hline \multicolumn{4}{|l|}{ Study design } & \multirow[t]{2}{*}{ Treatments } & \multirow[t]{2}{*}{ Study identifier } \\
\hline Regimen setting & Disease type & $\begin{array}{l}\text { Trial details } \\
\text { (estimated } \\
\text { enrolment) }\end{array}$ & Primary endpoint & & \\
\hline \multicolumn{6}{|c|}{ Non-metastatic disease } \\
\hline \multirow[t]{5}{*}{ Neo-adjuvant } & HER 2+ & $\begin{array}{l}\text { Phase I/II, OL, } \\
\text { SG (56) }\end{array}$ & $\mathrm{pCR}$ & Eribulin + carboplatin, trastuzumab & NCT01388647 [34] \\
\hline & HER2- & $\begin{array}{l}\text { Phase II, OL, SG } \\
\text { (47) }\end{array}$ & $\mathrm{pCR}$ & $\begin{array}{l}\text { Eribulin then dose-dense doxorubicin }+ \\
\text { cyclophosphamide }\end{array}$ & NCT01498588 [35] \\
\hline & HER 2- & $\begin{array}{l}\text { Phase II, R, PG, } \\
\text { OL (152) }\end{array}$ & $\mathrm{pCR}$ & Eribulin then FAC vs paclitaxel then FEC & NCT01593020 [36] \\
\hline & HER 2- & $\begin{array}{l}\text { Phase II, R, PG, } \\
\text { OL (76) }\end{array}$ & $\mathrm{pCR}$ & $\begin{array}{r}\text { Eribulin }+ \text { cyclophosphamide vs } \\
\text { docetaxel }+ \text { cyclophosphamide }\end{array}$ & NCT01527487 [37] \\
\hline & $\mathrm{TN}$ & $\begin{array}{l}\text { Phase II, SG, OL } \\
\text { (30) }\end{array}$ & $\mathrm{pCR}$ & Eribulin + carboplatin & NCT01372579 [38] \\
\hline \multirow[t]{3}{*}{ Adjuvant } & $\begin{array}{l}\text { TN, HER2+, } \\
\text { HER2 - }\end{array}$ & $\begin{array}{l}\text { Phase II, PG, OL } \\
\text { (148) }\end{array}$ & 2-year DFS & $\begin{array}{l}\text { Eribulin or eribulin }+ \text { trastuzumab in } \\
\text { patients who do not achieve pCR } \\
\text { following neo-adjuvant chemotherapy }\end{array}$ & NCT01401959 [39] \\
\hline & $\mathrm{ER}+$ & $\begin{array}{l}\text { Phase II, SG, OL } \\
\text { (67) }\end{array}$ & Feasibility & Eribulin + capecitabine & NCT01439282 [40] \\
\hline & NS & $\begin{array}{l}\text { Phase II, SG, OL } \\
\quad(80)\end{array}$ & Feasibility & $\begin{array}{l}\text { Dose-dense } \\
\text { doxorubicin }+ \text { cyclophosphamide then } \\
\text { eribulin }\end{array}$ & NCT01328249 [41] \\
\hline \multicolumn{6}{|l|}{ Metastatic disease } \\
\hline First-line & HER 2+ & $\begin{array}{l}\text { Phase II, SG, OL } \\
\text { (52) }\end{array}$ & ORR & Eribulin + trastuzumab & NCT01269346 [42] \\
\hline First-line & HER2- & $\begin{array}{l}\text { Phase II, SG, OL } \\
\text { (52) }\end{array}$ & ORR & Eribulin & NCT01268150 [44] \\
\hline Second-line & HER2- & $\begin{array}{l}\text { Phase II, R, PG, } \\
\text { OL (141) }\end{array}$ & PFS & Eribulin $+/-$ ramucirumab & NCT01427933 [45] \\
\hline Second-line & $\mathrm{TN}$ & $\begin{array}{l}\text { Phase I/II SG, } \\
\text { OL (80) }\end{array}$ & MTD, PFS & Eribulin + PLX 3397 & NCT01596751 [46] \\
\hline Fourth-line & NS & $\begin{array}{l}\text { Phase I/II, R, OL } \\
\text { (116) }\end{array}$ & $\begin{array}{l}\text { Tolerability, } \\
\text { response }\end{array}$ & Eribulin + capecitabine & NCT01323530 [47] \\
\hline NS & HER2 + & $\begin{array}{l}\text { Phase II, R, PG, } \\
\text { OL (80) }\end{array}$ & $\begin{array}{l}\text { TTP, } \\
\text { tolerability }\end{array}$ & Eribulin + lapatinib & NCT01534455 [43] \\
\hline NS & NS & $\begin{array}{l}\text { Phase I/II, SG, } \\
\text { OL (58) }\end{array}$ & MTD, CBR & Eribulin + cyclophosphamide & NCT01554371 [48] \\
\hline NS & NS & $\begin{array}{l}\text { Phase I, SG, OL } \\
\text { (54) }\end{array}$ & $\begin{array}{l}\text { Tolerability, } \\
\text { AUC, } C_{\max }, \\
\text { QT time }\end{array}$ & Eribulin + sorafenib & NCT01585870 [49] \\
\hline
\end{tabular}

$\overline{A U C}$ area under the drug concentration-time curve, $C B R$ clinical benefit rate, $C_{\max }$ peak drug concentration, $D F S$ disease-free survival, $E R$ oestrogen receptor, FAC fluorouracil + doxorubicin + cyclophosphamide, FEC fluorouracil + epirubicin + cyclophosphamide, HER2 human epidermal growth factor receptor 2, MTD maximum tolerated dose, $N S$ not specified, $O L$ open label, $O R R$ objective response rate, $p C R$ pathological complete response rate, $P F S$ progression-free survival, $P G$ parallel group, $R$ randomized, $S G$ single group, $T N$ triple negative, $T T P$ time to progression

In addition to eribulin, several novel cytotoxic chemotherapies have been evaluated in clinical trials (Table 7) and encouraging results have been reported [53, 54]. Traditional taxanes have large, complex molecular structures with hydrophobic and water-insoluble properties which require the drug be prepared with a toxic solvent, limiting the drug's clinical use. Therefore, many clinical studies investigating novel solvent-free formulations are ongoing.
Novel solvent-free taxane formulations include nanoparticle albumin-bound (nab)-paclitaxel, cationic liposomal paclitaxel (EndoTAG-1) and paclitaxel poliglumex (paclitaxel bound to a biodegradable poly-L-glutamic acid) (reviewed by Villanueva et al. [54]). Nab-paclitaxel is already available for breast cancer and is taking the place of solvent-based paclitaxel. Novel taxanes including larotaxel, tesetaxel and cabazitaxel and novel non-taxanes 
Table 7 New chemotherapeutic agents for breast cancer recently approved or in clinical trials $[53,54]$

\begin{tabular}{ll}
\hline Drug class & Agents (current phase in the trial) \\
\hline Anthracyclines & Liposomal doxorubicin (approved) \\
Antimetabolites & Pemetrexed (phase III) \\
$\begin{array}{c}\text { Antimicrotubule agents } \\
\text { (new formulation) }\end{array}$ & $\begin{array}{l}\text { Nanoparticle albumin-bound (nab)- } \\
\text { paclitaxel (approved) } \\
\text { EndoTAG-1 (phase II) }\end{array}$ \\
& $\begin{array}{l}\text { Paclitaxel poliglumex (phase II) } \\
\text { Antimicrotubule agents }\end{array}$ \\
$\begin{array}{l}\text { Larotaxel (phase II) } \\
\text { Tesetaxel (phase II) }\end{array}$ \\
Antimicrotubule agents & Cabazitaxel (phase II) \\
(novel non-taxane) & Influnine (phase III) \\
Platinum analogues & Satraplatin (phase II) \\
Topoisomerase inhibitor & NKTR-102 (phase III) \\
\hline
\end{tabular}

such as vinflunine and indibulin are being evaluated in phase II or III trials [54]. In contrast to other antimicrotubule agents, tesetaxel is orally active and is not a substrate for P-gp [54], and therefore may generate a new paradigm for breast cancer treatment. New agents of other classes are also in clinical development [53]; these include liposomal doxorubicin, the antimetabolite pemetrexed, the platinum analogue satraplatin and the irinotecan prodrug NKTR-102.

\section{Conclusions}

Because metastatic breast cancer remains incurable with currently available systemic therapies, novel approaches are crucial. Studies of eribulin have shown that the drug is effective in the treatment of previously treated metastatic breast cancer, and has an acceptable toxicity profile. Importantly, in the phase III EMBRACE study, eribulin treatment resulted in a survival advantage, a difficult endpoint to achieve with a single chemotherapeutic agent. An additional phase III study showed that eribulin has similar efficacy to capecitabine in women treated with no more than three prior therapies. Furthermore, pre-specified exploratory analyses suggest that particular patient subgroups may have greater therapeutic benefit with eribulin, and may warrant further study to explore the potential mechanisms behind these differences.

In addition, several classes of new cytotoxic chemotherapeutic agents are currently being evaluated in clinical trials and these promising agents may offer solutions to the difficult issues surrounding breast cancer. Considering the high efficacy of taxanes in breast cancer, new antimicrotubule agents including eribulin are expected to achieve the primary goals of systemic therapy, which are to prolong survival and improve quality of life, thereby realizing the wish of patients with an incurable disease to live longer and better.

Acknowledgments The original concept of this review was initiated by the author and he takes full responsibility for the intellectual content of this manuscript. The author would like to thank Sheridan Henness, $\mathrm{PhD}$, and Simone Boniface of inScience Communications, Springer Healthcare, who provided medical writing assistance. This medical writing assistance was funded by Eisai Co. Ltd.

Open Access This article is distributed under the terms of the Creative Commons Attribution Noncommercial License which permits any noncommercial use, distribution, and reproduction in any medium, provided the original author(s) and the source are credited.

\section{References}

1. GLOBOCAN. GLOBOCAN breast cancer fact sheet. 2013 . http://globocan.iarc.fr/factsheets/cancers/breast.asp. Accessed 16 Jan 2013

2. Jemal A, Bray F, Center MM, Ferlay J, Ward E, Forman D. Global cancer statistics. CA Cancer J Clin. 2011;61(2):69-90. doi: $10.3322 /$ caac. 20107

3. National Cancer Institute. SEER stat fact sheets: breast. http://seer.cancer.gov/statfacts/html/breast.html. Accessed 16 Jan 2013

4. Morris PG. Advances in therapy: eribulin improves survival for metastatic breast cancer. Anti-cancer Drugs. 2010;21(10):885-9. doi:10.1097/CAD.0b013e32833ed62e.

5. Cardoso F, Senkus-Konefka E, Fallowfield L, Costa A, Castiglione M. Locally recurrent or metastatic breast cancer: ESMO Clinical Practice Guidelines for diagnosis, treatment and follow-up. Ann Oncol. 2010;21(Suppl 5):v15-9. doi:10.1093/annonc/mdq160.

6. National Comprehensive Cancer Network. NCCN clinical practice guidelines in oncology (NCCN guidelines): breast cancer. Version 3. 2012. http://www.nccn.org/professionals/physician gls/pdf/breast.pdf. Accessed 15 Jan 2013.

7. Andre F, Zielinski CC. Optimal strategies for the treatment of metastatic triple-negative breast cancer with currently approved agents. Ann Oncol. 2012;23(Suppl 6):vi46-51. doi:10.1093/ annonc/mds 195 .

8. Ayoub JP, Verma S, Verma S. Advances in the management of metastatic breast cancer: options beyond first-line chemotherapy. Curr Oncol. 2012;19(2):91-105. doi:10.3747/co.19.1024.

9. Saji S, Sato F, Ueno NT. Fuel, electricity, ER and HER2-a hybrid-car model of breast cancer. Nat Rev Clin Oncol. 2012;9(7). doi:10.1038/nrclinonc.2012.9-c1.

10. Dufresne A, Pivot X, Tournigand C, Facchini T, Altweegg T, Chaigneau $\mathrm{L}$, et al. Impact of chemotherapy beyond the first line in patients with metastatic breast cancer. Breast Cancer Res Treat. 2008;107(2):275-9. doi:10.1007/s10549-007-9550-7.

11. Genentec Inc. Xeloda ${ }^{\circledR}$ (capecitabine) tablets. Prescribing information. 2011. http://www.gene.com/download/pdf/xeloda prescribing.pdf Accessed 16 Jan 2013.

12. Eisai Inc. Halaven ${ }^{\circledR}$ (eribulin mesylate) injection. Prescribing information. 2012. http://www.halaven.com/sites/default/files/ HALAVEN_full_Prescribing_Information.pdf. Accessed 16 Jan 2013.

13. Bristol-Myers Squibb. Ixempra ${ }^{\circledR}$ Kit (ixabepilone) for injection. 2011. http://packageinserts.bms.com/pi/pi_ixempra.pdf. Accessed 16 Jan 2013 
14. Aftimos P, Awada A. Survival benefit of eribulin mesylate in heavily pretreated metastatic breast cancer: what next? Adv Ther. 2011;28(11):973-85. doi:10.1007/s12325-011-0070-9.

15. Jordan MA, Kamath K, Manna T, Okouneva T, Miller HP, Davis $\mathrm{C}$, et al. The primary antimitotic mechanism of action of the synthetic halichondrin E7389 is suppression of microtubule growth. Mol Cancer Ther. 2005;4(7):1086-95. doi:10.1158/ 1535-7163.MCT-04-0345.

16. Smith JA, Wilson L, Azarenko O, Zhu X, Lewis BM, Littlefield BA, et al. Eribulin binds at microtubule ends to a single site on tubulin to suppress dynamic instability. Biochemistry. 2010;49(6):1331-7. doi:10.1021/bi901810u.

17. Ashley N, Poulton J. Mitochondrial DNA is a direct target of anticancer anthracycline drugs. Biochem Biophys Res Commun. 2009;378(3):450-5. doi:10.1016/j.bbrc.2008.11.059.

18. Eli Lilly and Co. Gemzar (gemcitabine for injection) powder, lyophilized, for solution for intravenous use. Prescribing information. http://pi.lilly.com/us/gemzar.pdf. Accessed 1 Mar 2013.

19. Kuhn JG. Fluorouracil and the new oral fluorinated pyrimidines. Ann Pharmacother. 2001;35(2):217-27.

20. Pasetto LM, D'Andrea MR, Brandes AA, Rossi E, Monfardini S. The development of platinum compounds and their possible combination. Crit Rev Oncol Hematol. 2006;60(1):59-75. doi: 10.1016/j.critrevonc.2006.02.003.

21. Pfizer. Camptosar (irinotecan) injection, intravenous infusion. Prescribing information. http://labeling.pfizer.com/ShowLabeling. aspx?id=533. Accessed 1 Mar 2013.

22. US Food and Drug Administration. FDA approves new treatment option for late-stage breast cancer. http://www.fda.gov/News Events/Newsroom/PressAnnouncements/2010/ucm233863.htm. Accessed 1 Mar 2013.

23. Eisai. Halaven ${ }^{\mathrm{TM}}$ (eribulin) receives European Commission approval for advanced breast cancer. http://www.eisai.com/news/ enews201125pdf.pdf. Accessed 1 Mar 2013.

24. Eisai. Halaven ${ }^{\circledR}$ receives approval in Japan for the treatment of inoperable and recurrent breast cancer. http://www.eisai.com/ news/enews201133pdf.pdf. Accessed 1 Mar 2013.

25. Tan AR, Rubin EH, Walton DC, Shuster DE, Wong YN, Fang F, et al. Phase I study of eribulin mesylate administered once every 21 days in patients with advanced solid tumors. Clin Cancer Res. 2009;15(12):4213-9. doi:10.1158/1078-0432.CCR-09-0360.

26. Mukohara T, Nagai S, Mukai H, Namiki M, Minami H. Eribulin mesylate in patients with refractory cancers: a phase I study. Invest New Drugs. 2012;30(5):1926-33. doi:10.1007/s10637011-9741-2.

27. Vahdat LT, Pruitt B, Fabian CJ, Rivera RR, Smith DA, Tan-Chiu E, et al. Phase II study of eribulin mesylate, a halichondrin B analog, in patients with metastatic breast cancer previously treated with an anthracycline and a taxane. J Clin Oncol. 2009;27(18):2954-61. doi:10.1200/JCO.2008.17.7618.

28. Cortes J, Vahdat L, Blum JL, Twelves C, Campone M, Roche H, et al. Phase II study of the halichondrin B analog eribulin mesylate in patients with locally advanced or metastatic breast cancer previously treated with an anthracycline, a taxane, and capecitabine. J Clin Oncol. 2010;28(25):3922-8. doi:10.1200/ JCO.2009.25.8467.

29. Aogi K, Iwata H, Masuda N, Mukai H, Yoshida M, Rai Y, et al. A phase II study of eribulin in Japanese patients with heavily pretreated metastatic breast cancer. Ann Oncol. 2012;23(6): 1441-8. doi:10.1093/annonc/mdr444.

30. Cortes J, O'Shaughnessy J, Loesch D, Blum JL, Vahdat LT, Petrakova K, et al. Eribulin monotherapy versus treatment of physician's choice in patients with metastatic breast cancer (EMBRACE): a phase 3 open-label randomised study. Lancet. 2011;377(9769):914-23. doi:10.1016/S0140-6736(11)60070-6.
31. Kaufman PA, Awada A, Twelves C, Yelle L, Perez EA, Wanders $\mathrm{J}$, et al. A phase III, open-label, randomized, multicenter study of eribulin mesylate versus capecitabine in patients with locally advanced or metastatic breast cancer previously treated with anthracyclines and taxanes [presentation S6-6]. In: San Antonio Breast Cancer Symposium; December 4-8, 2012; San Antonio, 2012.

32. Eisai. Phase III study (Study 301) results of anticancer agent Halaven ${ }^{\circledR}$ versus capecitabine in locally advanced or metastatic breast cancer presented at 2012 SABCS. http://www.eisai.com/ news/news201281.html. Accessed 25 Feb 2013.

33. Goel S, Mita AC, Mita M, Rowinsky EK, Chu QS, Wong N, et al. A phase I study of eribulin mesylate (E7389), a mechanistically novel inhibitor of microtubule dynamics, in patients with advanced solid malignancies. Clin Cancer Res. 2009;15(12): 4207-12. doi:10.1158/1078-0432.CCR-08-2429.

34. ACORN Research. Phase I/II study of neoadjuvant carboplatin, eribulin mesylate and trastuzumab $(\mathrm{ECH})$ for operable HER2 positive breast cancer [ClinicalTrials.gov identifier NCT01388647]. US National Institutes of Health, ClinicalTrials.gov [online]. http://www.clinicaltrials.gov/ct2/show/NCT0 1388647. Accessed 29 Jan 2013.

35. Emory University, Eisai. Phase II neoadjuvant trial of eribulin followed by dose dense doxorubicin and cyclophosphamide for Her2-negative, locally advanced breast cancer [ClinicalTrials.gov identifier NCT01498588]. US National Institutes of Health, ClinicalTrials.gov [online]. http://www.clinicaltrials.gov/ct2/ show/NCT01498588. Accessed 29 Jan 2013.

36. M.D. Anderson Cancer Center, Eisai. A randomized phase II neoadjuvant study of sequential eribulin followed by FAC/FECregimen compared to sequential paclitaxel followed by $\mathrm{FAC} /$ FEC-regimen in women with early stage breast cancer not overexpressing HER-2 [ClinicalTrials.gov identifier NCT01593020]. US National Institutes of Health, ClinicalTrials.gov [online]. http://www.clinicaltrials.gov/ct2/show/NCT0 1593020. Accessed 29 Jan 2013.

37. Sarah Cannon Research Institute, Eisai. A randomized phase II study of eribulin/cyclophosphamide or docetaxel/cyclophosphamide as neoadjuvant therapy in locally advanced HER2negative breast cancer [ClinicalTrials.gov identifier NCT01527487]. US National Institutes of Health, ClinicalTrials.gov [online]. http://www.clinicaltrials.gov/ct2/show/NCT0 1527487. Accessed 29 Jan 2013.

38. Northwestern University, Eisai. Phase II neoadjuvant trial with carboplatin and eribulin mesylate in triple negative breast cancer patients [ClinicalTrials.gov identifier NCT01372579]. US National Institutes of Health, ClinicalTrials.gov [online]. http://www.clinicaltrials.gov/ct2/show/NCT01372579. Accessed 29 Jan 2013.

39. Sarah Cannon Research Institute, Eisai. Phase II trial of eribulin in patients who do not achieve pathologic complete response (pCR) following neoadjuvant chemotherapy [ClinicalTrials.gov identifier NCT01401959]. US National Institutes of Health, ClinicalTrials.gov [online]. http://www.clinicaltrials.gov/ct2/ show/NCT01401959. Accessed 29 Jan 2013.

40. Eisai. A phase II, multicenter, single-arm, feasibility study of eribulin in combination with capecitabine for adjuvant treatment in estrogen receptor-positive early stage breast cancer [ClinicalTrials.gov identifier NCT01439282]. US National Institutes of Health, ClinicalTrials.gov [online]. http://www.clinicaltrials.gov/ ct2/show/NCT01439282. Accessed Jan 292013.

41. Eisai. A phase II, single-arm, feasibility study of dose dense doxorubicin and cyclophosphamide (AC) followed by eribulin mesylate for the adjuvant treatment of early stage breast cancer [ClinicalTrials.gov identifier NCT01328249]. US National 
Institutes of Health, ClinicalTrials.gov [online]. http://www. clinicaltrials.gov/ct2/show/NCT01328249. Accessed 29 Jan 2013.

42. Eisai. A phase 2, multicenter, single-arm study of eribulin mesylate with trastuzumab as first-line therapy for locally recurrent or metastatic human epidermal growth factor receptor two (HER2) positive breast cancer [ClinicalTrials.gov identifier NCT01269346]. US National Institutes of Health, ClinicalTrials.gov [online]. http://www.clinicaltrials.gov/ct2/show/NCT 01269346. Accessed 292013.

43. German Breast Group. A randomized phase II study to determine the efficacy and tolerability of two doses of eribulin plus lapatinib in trastuzumab pre-treated patients with HER2-positive metastatic breast cancer (E-VITA) [ClinicalTrials.gov identifier NCT01534455]. US National Institutes of Health, ClinicalTrials.gov [online]. http://www.clinicaltrials.gov/ct2/show/NCT 01534455. Accessed 29 Jan 2013.

44. Eisai. A phase 2, multicenter, single-arm study of single-agent eribulin mesylate as first-line therapy for locally recurrent or metastatic human epidermal growth factor receptor two (HER2) negative breast cancer [ClinicalTrials.gov identifier NCT01268150]. US National Institutes of Health, ClinicalTrials.gov [online]. http://www.clinicaltrials.gov/ct2/show/NCT01268150. Accessed 29 Jan 2013.

45. ImClone. An open-label, multicenter, randomized, phase 2 study evaluating the efficacy and safety of ramucirumab (IMC-1121B) drug product in combination with eribulin versus eribulin monotherapy in unresectable, locally-recurrent or metastatic breast cancer patients previously treated with anthracycline and taxane therapy [ClinicalTrials.gov identifier NCT01427933]. US National Institutes of Health, ClinicalTrials.gov [online]. http://www.clinicaltrials.gov/ct2/show/NCT01427933. Accessed 29 Jan 2013.

46. Rugo H, Susan G. Komen Breast Cancer Foundation, Plexxikon, Eisai. Enhancing efficacy of chemotherapy in triple negative/ basal-like breast cancer by targeting macrophages: a multicenter phase Ib/II study of PLX 3397 and eribulin in patients with metastatic breast cancer [ClinicalTrials.gov identifier NCT01596751]. US National Institutes of Health, ClinicalTrials.gov [online]. http://www.clinicaltrials.gov/ct2/show/NCT015 96751. Accessed 29 Jan 2013.

47. Eisai. A phase $1 b / 2$, multicenter, randomized, open-label, doseescalation and confirmation study of eribulin in combination with capecitabine [ClinicalTrials.gov identifier NCT01323530]. US National Institutes of Health, ClinicalTrials.gov [online]. http://www.clinicaltrials.gov/ct2/show/NCT01323530. Accessed 29 Jan 2013.

48. University of California, San Francisco, Eisai Inc. A phase Ib/II study of eribulin in combination with cyclophosphamide in patients with solid tumor malignancies [ClinicalTrials.gov identifier NCT01554371]. US National Institutes of Health, ClinicalTrials.gov [online]. http://www.clinicaltrials.gov/ct2/show/ NCT01554371. Accessed 29 Jan 2013.

49. Bayer. A phase 1, multi-center, non-randomized, open label, dose escalation design study of sorafenib (BAY43-9006) in combination with eribulin in subjects with advanced, metastatic or refractory solid tumors [ClinicalTrials.gov identifier NCT01585870]. US National Institutes of Health, ClinicalTrials.gov [online]. http://www.clinicaltrials.gov/ct2/show/NCT01585870. Accessed 29 Jan 2013.

50. Vahdat L, Schwartzberg L, Glück S, Rege J, Liao J, Cox D, et al. Results of a phase 2, multicenter, single-arm study of eribulin mesylate as first-line therapy for locally recurrent or metastatic HER2-negative breast cancer [presentation P1-12-02]. In: San Antonio Breast Cancer Symposium; December 4-8, 2012; San Antonio.

51. Vahdat L, Schwartzberg L, Wilks S, Rege J, Liao J, Cox D, et al. Eribulin mesylate + trastuzumab as first-line therapy for locally recurrent or metastatic HER2-positive breast cancer: results from a phase 2, multicenter, single-arm study [presentation P5-20-04]. In: San Antonio Breast Cancer Symposium; December 4-8, 2012; San Antonio.

52. Traina TA, Hudis C, Fornier M, Lake D, Lehman R, Berkowitz AP, et al. Adjuvant treatment of early-stage breast cancer with eribulin mesylate following dose-dense doxorubicin and cyclophosphamide: preliminary results from a phase 2, single-arm feasibility study [presentation P1-13-11]. In: San Antonio Breast Cancer Symposium; December 4-8, 2012; San Antonio.

53. Warsch S, Montero AJ, Glück S. Novel cytotoxic agents in the treatment of metastatic breast cancer. Curr Breast Cancer Rep. 2012;4:75-82. doi:10.1007/s12609-011-0066-0.

54. Villanueva CB, Bazan FF, Pivot XB. New microtubule inhibitors in breast cancer. Curr Breast Cancer Rep. 2013;5:1-10. doi: 10.1007/s12609-012-0101-9. 